\title{
Synthesis of Polysilane-Acrylic Copolymers by Photopolymerization and Their Application to Positive Resists for EB Lithography
}

\author{
Yukihito Matsuura*, Toshiyuki Tamai*, Kimihiro Matsukawa*, Hiroshi Inoue*, \\ Tetsuya Hamamoto**, Hiroshi Toyota**, and Kazuo Sato*** \\ * Osaka Municipal Technical Research Institute, 1-6-50 Morinomiya, Joto-ku, Osaka 536-8553, Japan \\ ** Osaka Science and Technology Center, 2-7-1 Ayumino, Izumi-city, Osaka 594-1157,Japan \\ ***Technology Research Institute of Osaka Prefecture, 2-7-1 Ayumino, Izumi-city, Osaka 594-1157, Japan \\ matsuura@omtri.city.osaka.jp
}

\begin{abstract}
Various polysilane-acrylic block copolymers have been prepared by photopolymerization of vinyl monomers using poly(methylphenylsilane) (PMPS) as a macromolecular photo-radical initiator. The block copolymers have been applied to positive resists for electron beam (EB) lithography. PMPS-methyl $\alpha$-chloroacrylate copolymer (P(MPS-co-MClA)) was found to have a good sensitivity to the EB irradiation, high heat resistance, and dry etching resistance.
\end{abstract}

Keywords: polysilane-acrylic block copolymer, photopolymerization, EB, positive resist

\section{Introduction}

Acrylic polymers have been known as sensitive positive resists for the EB lithography.[1] Poly(methyl methacrylate) (PMMA) and poly(methyl $\alpha$-chloroacrylate-co- $\alpha$-methylstyrene) ( $\mathrm{P}(\mathrm{MClA}-\mathrm{co}-\mathrm{MSt}))$ are mainly used as the typical commercial positive resists for the EB lithography.[2] The PMMA exhibits high resolution, and on the contrary, the $\mathrm{P}(\mathrm{MClA}-\mathrm{co}$ MSt) has high contrast and good sensitivity to EB irradiation. However, those polymers do not have sufficient heat resistance and dry etching resistance.[3]

Polysilane exhibits low sensitivity to EB irradiation. Furthermore, it has been thought to have low contrast for the use of practical lithographic process. [4] The high heat resistance and dry etching resistance of the polysilane, however, should be predictable from the $\mathrm{Si}$ skeleton.[5] In addition to the above interesting characters, polysilane has been known as photoinitiators for vinyl polymerizations. [6]

If EB sensitivity of polysilanes is improved to a level of PMMA and P(MClA-co-MSt) with keeping heat resistance and dry etching resistance intact, they can be used for not only microfabrication of LSI, but also fabrication of optical devices having a blazed structure, such as blazed micro-Fresnel lenses, because of their suitable $\gamma$-value. [7] Recently, we have successfully synthesized a polysilane-methacrylic block copolymer using the polysilane as a macromolecular photo-radical initiator.[8] In this paper, we report the synthesis of various polysilane-acrylic block copolymers (Fig.1) and the lithographic properties of the thin films of the products.

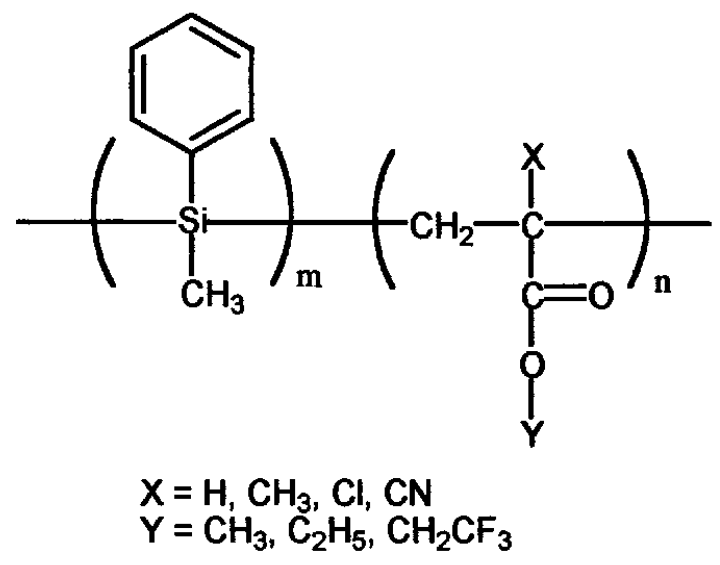

Fig. 1 Chemical structures of polymethylphenylsilaneacrylic block copolymers. 


\section{Experimental}

(1) Synthesis of polysilane-acrylic block copolymers

PMPS was supplied by Osaka Gas Corporation: $\mathrm{Mn}=9.18 \times 10^{3}, \mathrm{Mw} / \mathrm{Mn}=1.54$, and $\lambda_{\max }=336.6 \mathrm{~nm}$. The vinyl monomers used in the photopolymerization with the PMPS were $n$-butyl acrylate (BuA, Wako Pure Chemical Industries, Ltd. ) , methyl methacrylate (MMA, Kanto Chemical Co.) , 2,2,2-trifluoroethyl methacrylate

(TFEM, Osaka Organic Chemical Industry), methyl $\alpha$-chloroacrylate (MClA, Kanto Chemical Co. ), ethyl $\alpha$-cyanoacrylate (ECnA, Taoka Chemical Industry), methacrylonitrile (MAn, Tokyo Kasei Kogyo Co.) , 2-chlorocyanoethylene (ClCnE, Tokyo Kasei Kogyo Co.) , styrene (St, Wako Pure Chemical Industires, Ltd.), and $\alpha$ methylstyrene ( MSt, Wako Pure Chemical Industires, Ltd.) . Fig.2 shows the molecular structures of the vinyl monomers $\mathrm{BuA}, \mathrm{MMA}$, TFEM, MAn, ClCnE, St, and MSt were used after vacuum distillation because the commercial reagents contained stabilizers to prevent the polymerization. MClA and ECnA, on the contrary, were used without purification because of their high reactivity.

The photopolymerization was carried out using PMPS as a macromolecular photo-radical initiator. [8] Vinyl monomer and PMPS were dissolved in toluene and the mixture was sufficiently degassed by the freeze-thaw method. After sealing the tube under reduced pressure, the tube was irradiated by UV light (high pressure $\mathrm{Hg}$ lamp; $10 \mathrm{~mW} / \mathrm{cm}^{2}$ ) at room temperature for a limited time. The products obtained from the photopolymerization were purified by reprecipitation from 2-propanol, followed by filtering and vacuum drying. The photopolymerization conditions for the synthesis are represented in Table 1.

\section{(2) Measurements}

Gel permeation chromatography (GPC) was done with a Toyo-soda HLC-8020. Molecular weights were calibrated using polystyrene standards. ${ }^{1} \mathrm{H}-\mathrm{NMR}$ spectra were recorded on a JEOL NMR-270. Infrared spectra were measured with a Nicolet Impact 420M Fourier-transform spectrophotometer. UV-vis spectra were<smiles>C=CC(=O)OCC</smiles><smiles>C=C(C)C(=O)OC</smiles>

MMA<smiles>C=C(C)C(=O)OCC(F)(F)F</smiles>

TFEM<smiles>C=C(Cl)C(=O)OC</smiles>

MClA<smiles>C=C(C#N)C(=O)OCC</smiles>

ECnA<smiles>C=C(C)C#N</smiles><smiles>C=C(Cl)C#N</smiles><smiles>C=Cc1ccccc1</smiles><smiles>C=C(C)c1ccccc1</smiles>

MAn

ClCnA

St

MSt

Fig.2 Molecular structures of vinyl monomers for photopolymerizaton with PMPS. 
recorded on a Hitachi U-3210. Thermogravimetric and differential thermal analyses (TG-DTA) were performed using a SEIKO SSC-5200 under $\mathrm{N}_{2}$ flow. The heating rate was $10^{\circ} \mathrm{C} / \mathrm{min}$.

\section{(3) EB Lithography}

The solutions for spin-coating were prepared by dissolving the products in toluene by $5-10$ weight percent and then were filtered through a 0.2 $\mu \mathrm{m}$ filter. The thin films of the polymers were formed on substrates $\left(\mathrm{Si}\right.$ and $\mathrm{SiO}_{2}$ ) by spin-coating of the solution at $2000 \mathrm{rpm}$ and then baked at $90{ }^{\circ} \mathrm{C}$ for $60 \mathrm{~min}$ in air. The thickness of the thin films was measured using an ellipsometry (ULVAC ESM-1). The EB exposure was carried out using a JEOL JBX-5000SI. The thin films were irradiated with $\mathrm{EB}$ of which acceleration voltage was $50 \mathrm{kV}$, and then the thin films were developed by 2-propanol for $60 \mathrm{sec}$. The reactive ion etching $i$. $e$., dry etching, was carried out using a ULVAC NLD-800. The etching conditions were as follows: antenna power of $1500 \mathrm{~W}$; bias power of $400 \mathrm{~W}$; pressure of $0.6 \mathrm{~Pa}$; etching time of $1 \mathrm{~min} ; \mathrm{C}_{4} \mathrm{~F}_{8}$ flow of $16 \mathrm{sccm} ; \mathrm{CH}_{2} \mathrm{~F}_{2}$ flow of 14 $\mathrm{sccm} ; \mathrm{O}_{2}$ flow of $3 \mathrm{sccm}$.

\section{Results and Discussion}

(1) Characterization of polysilane-acrylic copolymers

Results of photopolymerization are shown in Table 1. The molecular weight distribution of all products was monomodal. Molecular weights of A-1, B-1, C-1, D-1, and E-1 varied little from that of PMPS as the starting material at an irradiation time of 10-20 min. Moreover, F, G, H, and I did

Table 1. Photopolymerization conditions and characterization of the products.

\begin{tabular}{|c|c|c|c|c|c|c|c|c|c|}
\hline \multirow[t]{2}{*}{ Sample No. } & \multirow[t]{2}{*}{ Vinyl monomer } & \multirow[t]{2}{*}{ Feed ratio $^{a}$} & \multirow[t]{2}{*}{ Time $(\min )^{\mathrm{b}}$} & \multicolumn{4}{|c|}{ Copolymer } & \multirow[b]{2}{*}{$\lambda \max (\mathrm{mm})^{d}$} & \multirow[b]{2}{*}{$T_{d}\left({ }^{\circ} \mathrm{C}\right)^{\circ}$} \\
\hline & & & & Yield (\%) & $\mathbf{M n}$ & $\mathrm{Mw} / \mathrm{Mn}$ & $m / n^{c}$ & & \\
\hline$\overline{A-1}$ & BuA & $0.5 \mathrm{~g} / 0.5 \mathrm{~g}$ & 20 & 25.0 & $8.96 \times 10^{3}$ & 1.97 & $70.1 / 29.9$ & 331.2 & - \\
\hline$A-2$ & $"$ & $0.5 \mathrm{~g} / 0.5 \mathrm{~g}$ & 40 & 8.0 & $4.65 \times 10^{3}$ & 1.86 & $68.0 / 32.0$ & 325.4 & 331 \\
\hline$A-3^{f}$ & $"$ & $0.5 \mathrm{~g} / 0.5 \mathrm{~g}$ & 60 & - & - & - & - & - & - \\
\hline B-1 & MMA & $0.5 \mathrm{~g} / 0.4 \mathrm{~g}$ & 20 & 52.1 & $1.10 \times 10^{4}$ & 1.72 & $88.5 / 11.5$ & 334.4 & - \\
\hline B-2 & $"$ & $0.5 \mathrm{~g} / 0.4 \mathrm{~g}$ & 40 & 56.2 & $4.90 \times 10^{4}$ & 1.59 & $64.5 / 35.5$ & 320.6 & 317 \\
\hline B- $3^{f}$ & $"$ & $0.5 \mathrm{~g} / 0.4 \mathrm{~g}$ & 60 & - & - & - & - & - & - \\
\hline C-1 & TFEM & $0.5 \mathrm{~g} / 0.6 \mathrm{~g}$ & 20 & 22.0 & $9.46 \times 10^{3}$ & 1.56 & $97.5 / 2.5$ & 328.8 & - \\
\hline$C-2^{f}$ & $n$ & $0.5 \mathrm{~g} / 0.6 \mathrm{~g}$ & 40 & - & - & - & - & - & - \\
\hline D-1 & MClA & $0.5 \mathrm{~g} / 0.4 \mathrm{~g}$ & 10 & 47.0 & $9.32 \times 10^{4}$ & 1.61 & $81.6 / 18.4$ & 335.6 & - \\
\hline D-2 & $"$ & $0.5 \mathrm{~g} / 0.4 \mathrm{~g}$ & 20 & 51.0 & $1.17 \times 10^{4}$ & 1.86 & $73.7 / 26.3$ & 335.4 & 342 \\
\hline$D-3^{g}$ & $"$ & $0.5 \mathrm{~g} / 0.4 \mathrm{~g}$ & 40 & - & - & - & - & - & - \\
\hline E-1 & ECnA & $0.5 \mathrm{~g} / 0.5 \mathrm{~g}$ & 10 & 43.8 & $9.86 \times 10^{3}$ & 1.84 & $96.7 / 3.3$ & 335.2 & - \\
\hline E-2 & $n$ & $0.5 \mathrm{~g} / 0.5 \mathrm{~g}$ & 20 & 36.0 & $1.02 \times 10^{4}$ & 1.57 & $67.0 / 33.0$ & 334.8 & 138,380 \\
\hline$E-3^{g}$ & $"$ & $0.5 \mathrm{~g} / 0.5 \mathrm{~g}$ & 40 & - & - & - & - & - & - \\
\hline$F^{h}$ & MAn & $0.5 \mathrm{~g} / 0.3 \mathrm{~g}$ & 40 & 52.3 & $9.42 \times 10^{3}$ & 1.88 & $100 / 0$ & - & - \\
\hline$G^{h}$ & $\mathrm{CKCnE}$ & $0.5 \mathrm{~g} / 0.3 \mathrm{~g}$ & 40 & 48.7 & $1.03 \times 10^{4}$ & 1.91 & $100 / 0$ & - & - \\
\hline $\mathbf{H}^{\mathbf{h}}$ & St & $0.5 \mathrm{~g} / 5.0 \mathrm{~g}$ & 40 & 7.1 & $9.02 \times 10^{3}$ & 2.14 & $100 / 0$ & - & - \\
\hline $\mathrm{I}^{\mathrm{h}}$ & $\mathbf{M S t}$ & $0.5 \mathrm{~g} / 5.0 \mathrm{~g}$ & 40 & 7.7 & $9.10 \times 10^{3}$ & 1.89 & $100 / 0$ & - & - \\
\hline
\end{tabular}

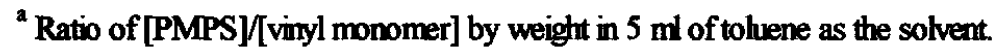

${ }^{b}$ Irradiation time of UV light in which light intensity was $10 \mathrm{~mW} / \mathrm{cm}^{2}$.

${ }^{c}$ Molar ratio of [methylphenylsilane][vinyl monomer] determined by the ${ }^{1} \mathrm{H}$-NMR spectra.

${ }^{d}$ Wavelength at the UV absorption maximum

${ }^{\mathbf{e}}$ Decomposition temperature measured using TG-DTA.

f Oligomerization occurred.

${ }^{8}$ Gelation occurred.

${ }^{\mathrm{h}}$ The UV-vis absorption spectra have not been measured.
} 
not indicate any remarkable change in molecular weight even after an irradiation time of $40 \mathrm{~min}$. At a longer irradiation time of $40-60 \mathrm{~min}$, a considerable reduction in molecular weight occurred in A-3, B-3, and C-2, of which molecular weight could not be measured because they completely passed through a glass filter (20-30 $\mu \mathrm{m}$ of porosity) after reprecipitation with 2-propanol. It is considered that the small oligomeric fragments were produced from the decomposition of PMPS. In the cases of D-3 and E-3, on the other hand, gelation took place upon UV irradiation at an irradiation time of $40 \mathrm{~min}$.

The FT-IR spectra of A-1, A-2, B-1, B-2, C1, D-1, D-2, E-1, and E-2 indicated carbonyl peaks around $1730-1760 \mathrm{~cm}^{-1}$ in addition to the major peaks of PMPS. A proton peak around 3.5-4.5 ppm in the ${ }^{1} \mathrm{H}-\mathrm{NMR}$ spectra of A-1, A-2, B-1, B-2, C-1, D-1, D-2, E-1, and E-2 were due to protons of $-\mathrm{CO}-\mathrm{O}-\mathrm{CH}_{2}-$ or $-\mathrm{CO}-\mathrm{O}-\mathrm{CH}_{3}$ group. From the quantitative analysis of the ${ }^{1} \mathrm{H}-\mathrm{NMR}$ spectra, A-2, B-2, D-2, and E-2 were found to have a relatively high content of the vinyl monomers. Both the FT-IR and ${ }^{\mathrm{l}} \mathrm{H}-\mathrm{NMR}$ spectra of F, G, H, and I had no peak except for those of PMPS, and therefore it is considered that $\mathrm{MAn}, \mathrm{ClCnE}, \mathrm{St}$, and MSt are unreactive to PMPS under those conditions. The detailed data of the FT-IR and ${ }^{1} \mathrm{H}-\mathrm{NMR}$ spectra are reported in the reference.[9]

In general, polysilanes are well-known to have a strong absorption peak due to $\sigma-\sigma^{*}$ transition of $\mathrm{Si}-\mathrm{Si}$ bond in the UV-visible region.[3] Moreover, the absorption peak shifts to shorter wavelength and absorbance decreases as the polysilane chain becomes shorter. A strong absorption around $330 \mathrm{~nm}$ in the spectra of the products decreased with UV irradiation (as indicated later). Therefore, it is considered that the absorption around $330 \mathrm{~nm}$ in the products is due to $\sigma-\sigma^{*}$ transition of PMPS main chain. Moreover, the wavelength of $\sigma-\sigma^{*}$ transition in A-1, A-2, B-1, B-2, C-1, D-1, D-2, E-1, and E-2 shifted to shorter wavelength, hence suggesting that the chain length of PMPS in the copolymers became shorter than that of PMPS as the starting material. Particularly, in the case of A-2, B-2, and $\mathrm{C}-1$, the tendency was remarkable.

From the above measurements, it was considered for A-1, A-2, B-1, B-2, C-1, D-1, D-2, $\mathrm{E}-1$, and $\mathrm{E}-2$ to be the PMPS-acrylic block copolymers. The acrylic monomers tend to react with PMPS silyl radicals generated under UV irradiation, forming the PMPS block copolymers.
In the longer irradiation time, the acrylic monomers except for MCIA and ECnA tend to let their PMPS-acrylic block copolymers oligomerize and furthermore the fluorine atoms of the alkoxy group in the monomer (TFEM) accelerates the oligomerization. $\alpha$-Chloro- and $\alpha$-cyano-acrylic monomers (MClA and ECnA), on the contrary, were found to bring about the gelation of the products after the longer irradiation time, probably due to photo-scission of $\alpha$-substituents, followed by crosslinking.

\section{(2) Thermal and lithographic properties}

The decomposition temperature $\left(T_{d}\right)$ of the products was examined using TG-DTA. Fig.3 shows the TG curves of the products, and the values of $T_{d}$ are summarized in Table 1 . The $T_{d}$ of the products was higher than that of PMMA $\left(T_{d} \sim 310^{\circ} \mathrm{C}\right.$ ), although these values were lower than that of PMPS $\left(T_{d}=387{ }^{\circ} \mathrm{C}\right)$. Among the products, D-2 had a relatively higher value of $T_{d}$ in spite of the relatively large amount of acrylic block. In a case of E-2, there were two $T_{d}$ in the TG curve. It is considered that the low $T_{d}$ at $138{ }^{\circ} \mathrm{C}$ is due to the decomposition of acrylic block and, on the other hand, the high $T_{d}$ at $380{ }^{\circ} \mathrm{C}$ due to PMPS block. These results indicate that the E-2 has much lower heat resistance than the other products, attributable to lower bond energy of poly $(\alpha$-cyano acrylate) main chain.

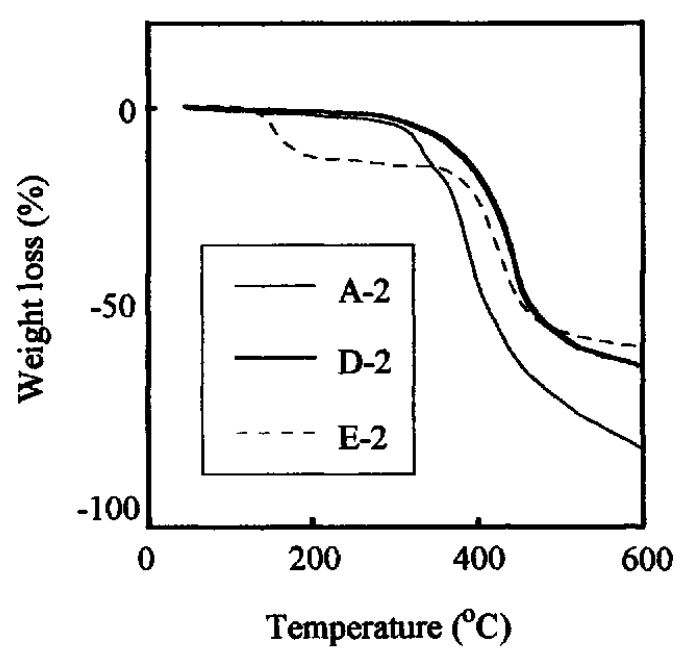

Fig. 3 TG curves of the A-2, D-2, and E-2 under $\mathrm{N}_{2}$ atmosphere. 
Fig. 4 shows the EB sensitivity curves of the products. The sensitivity of D-2 thin film was $140 \mu \mathrm{C} / \mathrm{cm}^{2}$, which is almost equivalent to that of PMMA and/or P(MClA-co-MSt) $\left(10 \sim 100 \mu \mathrm{C} / \mathrm{cm}^{2}\right)$ and much higher than that of PMPS (about 1000 $\mu \mathrm{C} / \mathrm{cm}^{2}$ ). In a high dose of $400-1000 \mu \mathrm{C} / \mathrm{cm}^{2}$, the patterns were disturbed by the near-field effect. Although the resolution has not yet been confirmed by scanning electron microscope because of thinner film thickness, $1.0 \mu \mathrm{m} \mathrm{L} / \mathrm{S}$ was observed using an optical microscope. If the lithographic conditions are optimized, it is expected to show a much higher resolution. The relative etching resistance (selectivity to $\mathrm{SiO}_{2}$ in dry etching resistance) was 5.28 , which is a much higher value than those of PMMA and P(MSt-co-MClA) (about 2-3).

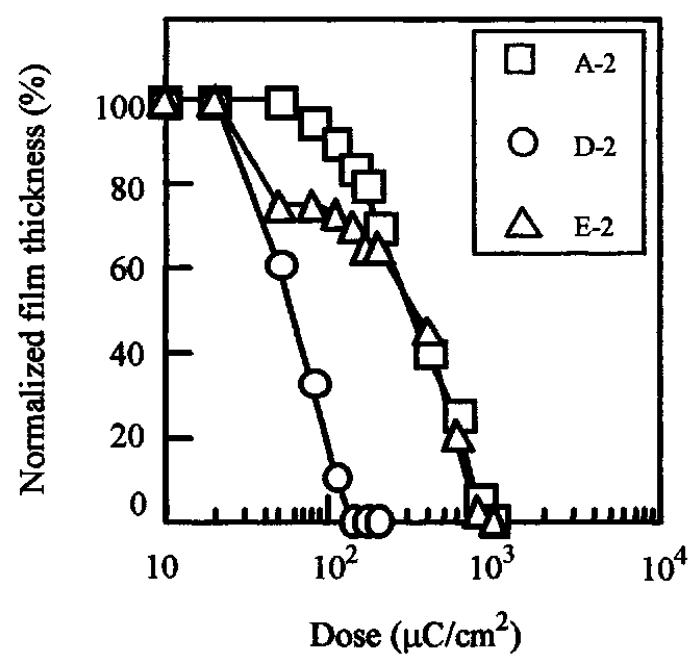

Fig. 4 EB lithographic properties of A-2, D-2, and E-2.

The thin films of A-2 and E-2 had a relatively lower sensitivity to EB than that of D-2. As shown in Fig.4, in a case of E-2, the film thickness developed decreased with the two-step dissolution depending on the dose of the EB irradiation, therefore indicating that E-2 was decomposed by EB irradiation with two-cleavage process along the main chain, that is, $\mathrm{C}-\mathrm{C}$ bond as first step and $\mathrm{Si}-\mathrm{Si}$ bond as second step. These results are consistent with the view of the two-step decomposition in the TG curve of the E-2. We have also tried the EB lithography for B-2 and C1 thin films. However, we have not yet found optimum development conditions for the B-2 thin film, and the C-1 thin film had a low sensitivity because of the large amount of PMPS block.
From the above thermal and EB lithographic properties, it is concluded that P(MPS-co-MClA) (D-2) is the most suitable for the EB lithography.

The sensitivity of D-2 to UV light was examined by monitoring the absorbance at $\lambda_{\max }$ as an index of the polysilane photodegradation. Fig.5 shows the UV-vis spectral change of PMPS and D-2 by the UV irradiation using an Ushio UV SPOT CURE SP-V. The other products showed the same tendency. From those results, it is evident that both the thin films had almost the same sensitivity to UV light and also much better one than that of acrylic polymers $\left(1000 \mathrm{~mJ} / \mathrm{cm}^{2}\right)$.

(a)

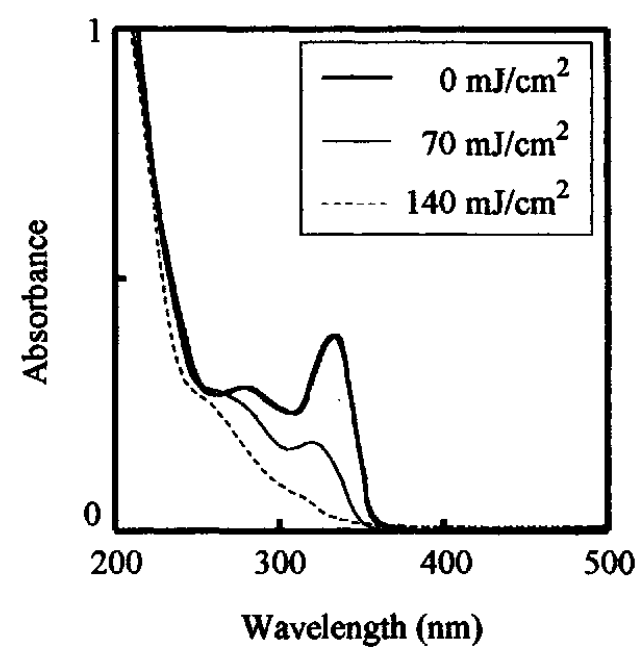

(b)

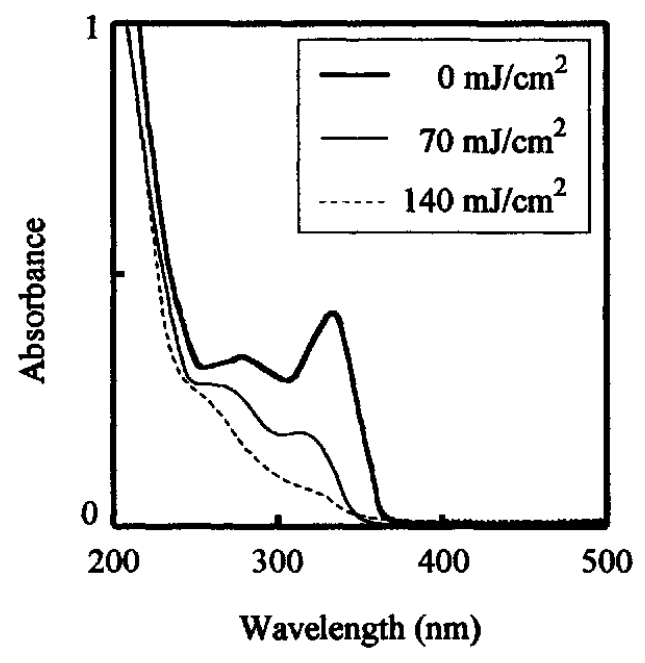

Fig. 5 UV-vis absorption spectra of (a) PMPS and (b) D-2 after UV irradiation. 


\section{Conclusion}

Polysilane-acrylic copolymers were prepared from the photopolymerization of acrylic monomers with PMPS. P(MPS-co-MClA) had a high heat resistance and excellent dry etching resistance in addition to a good sensitivity to EB irradiation, almost same level of PMMA and P(MClA-coMSt).

\section{Acknowledgment}

This work was performed for "Development of Basic Tera Optical Information Technologies" , Joint-Research Project for Regional Intensive in Osaka Prefecture, JST.

\section{References and notes}

1. M. Hatzakis, J. Electrochem. Soc., 116 (1969) 1033; H. F. Mark, N. H. Bikales, C. G. Overberger, G. Menges, and J. I. Kroschwitz, "Encyclopedia of Polymer Science and Technology," Vol. 9 (1987) 119, John Wiley \& Sons, New York.

2. G. M. Wallraff and W. D. Hinsberg, Chem. Rev., 99 (1999) 1801.

3. T. Nishida, M. Notomi, R. Iga, and T. Tamamura, Jpn. J. Appl. Phys., 31 (1992) 4508; T. Shibata, T. Ishii, H. Nozawa, and T. Tamamura, Jpn. J. Appl. Phys., 36 (1997) 7642.

4. R. D. Miller and J. Michl, Chem. Rev., 9 (1989) 1359; R. D. Miller, G. Wallraff, N. Clecak, R. Sooriyakumaran, J. Michl, T. Karamatsu, A. J. McKinlet, and K. A. Klingensmith, Polym. Eng. Sci., 29 (1989) 882; J. M. Zeigler and F. W. G. Fearon, "Silicon-Based Polymer Science," Advances in Chemistry Series, 224 (1990) American Chemical Society, Washington, D. C.,.

5. E. Reichmanis, G. Smolinsky, and C. W. Wilkins. Jr., Solid State Technol., 28 (1983) 130; D. C. Hofer, R: D. Miller, and C. G. Willson, Proc. SPIE Adv. Resist Technol., 469 (1984) 16.

6. P. Trefonas III, R. West, and R. D. Miller, $J$.
Am. Chem. Soc., 1072737 (1985); R. West, A.

R. Wolff, and D. J. Peterson, J. Rad. Curing, 13

(1986) 35; A. W. Wolff and R. West, Appl. Organomet. Chem., 1 (1987) 7; D. Yucesan, H. Hostygar, S. Denizligil, and Y. Yagci, Angew. Macromol. Chem., 221 (1994) 207.

7. T. Fujita, H. Nishihara, and J. Koyama, Opt. Lett., 6 (1981) 613; T. Shiono and K. Setsune, Opt. Lett., 15 (1990) 84; T. Shiono and H. Ogawa, Appl. Opt., 30 (1991) 3643; P. D. Maker and R. E. Muller, J. Vac. Sci. Tech., B10 (1992) 2516; D. Mikolas, R. Bojko, H. G. Craighead, F. Haas, D. A. Honey, and H. F. Bare, J. Vac. Sci. Tech., B12 (1994) 20; E. Di Fabrizio, L. Grella, M. Baciocchi, M. Gentili, D. Peschiaroli, L. Mastrogiacomo, and R. Maggiora, J. Vac. Sci. Tech., B14 (1996) 3855; E. B. Key, Microelectron Eng., 34 (1997) 261.

8. K. Matsukawa, S. Fukui, N. Higashi, M. Niwa, and H. Inoue, Chem. Lett., (1999) 1073; Y. Matsuura, K. Matsukawa, and H. Inoue, Chem. Lett., (2001) 244.

9. (PMPS) ${ }^{1} \mathrm{H}-\mathrm{NMR}\left(\mathrm{CDCl}_{3}, \delta\right.$ in ppm): $0.2-0.5(\mathrm{Si}-$ $\mathrm{CH}_{3}$ ) and 6.2-7.5(Ar-H); FT-IR( $\left(\mathrm{cm}^{-1}\right)$ : 690, 731, $750,780,1097,1240,1420,2962$, and 3060 . The characteristic peaks of the products except for those assigned to the functional groups in PMPS are as follows: (A-1 and A-2) ${ }^{1} \mathrm{H}-$ $\mathrm{NMR}\left(\mathrm{CDCl}_{3}, \delta\right.$ in ppm): $0.6-1.0\left(\mathrm{C}-\mathrm{CH}_{3}\right), 1.7-$ 2.3 $\left(\mathrm{C}-\mathrm{CH}_{2}\right)$, and 3.8-4.0(O-CH $\mathrm{CH}_{2}$; FT-IR $\left(\mathrm{cm}^{-1}\right)$ : $1066,1165$, and 1734. (B-1 and $\mathrm{B}-2){ }^{1} \mathrm{H}-$ $\mathrm{NMR}\left(\mathrm{CDCl}_{3}, \delta\right.$ in ppm): $0.6-1.0\left(\mathrm{C}-\mathrm{CH}_{3}\right), 1.7-$ 2.0 $\left(\mathrm{C}-\mathrm{CH}_{2}\right)$, and 3.5-3.7( $\left(\mathrm{O}-\mathrm{CH}_{3}\right)$; FT-IR $\left(\mathrm{cm}^{-1}\right)$ : 1731. (C-1) ${ }^{1} \mathrm{H}-\mathrm{NMR}\left(\mathrm{CDCl}_{3}, \delta\right.$ in ppm): 0.8$1.2\left(\mathrm{C}-\mathrm{CH}_{3}\right), \quad 1.9-2.1\left(\mathrm{C}-\mathrm{CH}_{2}\right)$, and $4.2-4.5(\mathrm{O}-$ $\left.\mathrm{CH}_{2}-\mathrm{CF}_{3}\right)$; FT-IR( $\left(\mathrm{cm}^{-1}\right): 1176,1282$, and 1740 . (D-1 and D-2) ${ }^{1} \mathrm{H}-\mathrm{NMR}\left(\mathrm{CDCl}_{3}, \delta\right.$ in ppm): $2.3-$ 3.2 $\left(\mathrm{C}-\mathrm{CH}_{2}\right)$ and 3.7(O-CH$)$; FT-IR $\left(\mathrm{cm}^{-1}\right)$ : 1728 and 1757. (E-1 and E-2) ${ }^{1} \mathrm{H}-\mathrm{NMR}\left(\mathrm{CDCl}_{3}, \delta\right.$ in ppm): $1.4\left(\mathrm{OCH}_{2}-\mathrm{CH}_{3}\right), \quad 2.5-2.8\left(\mathrm{C}-\mathrm{CH}_{2}\right)$, and 4.3(O-CH $\left.\mathrm{CH}_{2}\right) ; \quad$ FT-IR $\left(\mathrm{cm}^{-1}\right)$ : 1748 and 2240. 